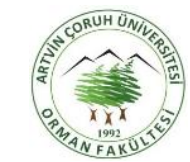

\title{
Bursa Orman Bölge Müdürlüğü sınırlarında bulunan bazı odunsu bitki türleri ile kurulabilecek potansiyel bal ormanı alanlarının belirlenmesi
}

\author{
Determination of potential honey forest areas with some woody plant species in Bursa Forest Regional Directorate \\ borders
}

Turan SÖNMEZ $\mathbb{D}$, Burhan GENCAL $\mathbb{D}$

Bursa Teknik Üniversitesi Orman Fakültesi Orman Mühendisliği Bölümü, Bursa Türkiye

\begin{tabular}{l}
\hline Eser Bilgisi/Article Info \\
Araştırma makalesi/Research article DOI: \\
$10.17474 /$ artvinofd.486880 \\
Sorumlu yazar/Corresponding author \\
Burhan GENCAL \\
e-mail: burhan.gencal@btu.edu.tr \\
Geliş tarihi / Received \\
23.11.2018 \\
Düzeltme tarihi/Received in revised form \\
28.03.2019 \\
Kabul Tarihi / Accepted \\
17.06.2019 \\
Elektronik erişim / Online available \\
01.07.2019 \\
Anahtar kelimeler: \\
Bal ormanı \\
Coğrafi bilgi sistemleri \\
Uzaktan algılama \\
Ihlamur \\
Kestane \\
Keywords: \\
Honey forest \\
Geographical information systems \\
Remote sensing \\
Linden \\
Chestnut \\
\hline
\end{tabular}

\begin{abstract}
Özet
Ülkemiz; zengin bitki örtüsü, farklı iklim ve coğrafik özellikleri ile arıcılığa son derece elverişli bir ortam oluşturmaktadır. Türkiye bulunduğu coğrafya, iklim koşulları ve bitki örtüsü ile ideal bir arıcılık bölgesidir. İstatistiklere bakıldığında ise Türkiye gerek arıcılıkla uğraşanlar gerekse kovan varlığı bakımından üst sıralarda olmasına rağmen bal, propolis, arı sütü gibi üretilen arı ürünleri bakımından birçok ülkeden geride bulunmaktadır. Bursa ili içerisinde 2013-2016 yılları arasında toplamda 725,3 hektar alanda 5 adet Bal Ormanı kurulmuş olup yapılan çalışmalar sonucunda 2016 yılından itibaren bu sayı 17 olmuştur. Bu çalışmamızda, Bursa Orman Bölge Müdürlüğü sınırları içerisinde bulunan bazı odunsu türlerle kurulabilecek Bal Ormanlarının, Coğrafi Bilgi Sistemleri (CBS) ve Uzaktan Algılama (UA) teknolojileri kullanılarak belirlenmesi ve yörede kurulacak bal ormanları ile bölgesel ve ulusal bağlamda elde edilecek gelirin tahmin edilmesi amaçlanmıştır. Alanların belirlenmesinde gerekli olan kriterlere Bal Ormanı Eylem Planından erişilmiştir. Yapılan analizler sonucunda odunsu türler bazında Bursa Orman Bölge Müdürlüğü sınırları içerisinde bal ormanına konu olabilecek alanlar belirlenmiştir.
\end{abstract}

\begin{abstract}
Our country, with its rich vegetation, different climate, and geographic features, creates an extremely favorable environment for beekeeping. Turkey has an ideal beekeeping region with climatic conditions and vegetation. Statistics shows that Turkey should apiculture bee products produced, although higher rankings for the presence of both sleeves is situated behind many countries. In this study, it is aimed to determine the Honey Forests, which can be established with some woody species within the boundaries of Bursa Forest Regional Directorate, using Geographical Information Systems (GIS) and Remote Sensing (UA) technologies. The criteria required for the determination of the areas were reached from the Honey Forest Action Plan. It is aimed to estimate the income to be brought to the region and our country. Because of the analyzes, the areas that may be subject to the honey forest within the boundaries of Bursa Forest Regional Directorate were determined based on woody species.
\end{abstract}

\section{GiRiş}

Dünyadaki en önemli varlıklardan biri olan arılar, tozlayıcı özelliğinin yanı sıra toprağı da koruyarak otsu ve odunsu bitkilerin dağılımında görev almaktadır. Arılar ve ormanlar karşılıkı bir yaşam tarzı benzemektedir. Bu yaşam tarzı sonucunda, erozyonu önlemeye katkılarıyla beraber endemik bitkilerin korunmasında da aktif olarak görev almaktadırlar. Arıların olmadığı bir dünyada özellikle endemik türlerin yok olabileceği ve erozyonların meydana gelebileceği düşünülmektedir (Crane 1972).

Gıda maddelerinin büyük bir çoğunluğunu oluşturan bitki türlerinin \%77'si arı aracılığıyla tozlaşmaya gerek duymaktadır. Özellikle bazı türler için tozlaşma elzemdir. Besin ihtiyacımızın \%33'ü ise direkt olarak tozlaşma sonucu oluşan bitkilerden meydana gelmektedir (Crane 1975).

Günümüzdeki dünya nüfusunun artışı aynı zamanda temel gıda, mal ve hizmetleri artırırken bu doğrultuda nicelik ve nitelik olarak da orantısal bir artış görmekteyiz. Nüfus artışı sonucunda artan intiyaçlar ve beklentiler de insanların ormanlardan daha fazla yararlanmasını ortaya çıkarmaktadır. Orman yönetimi ve kaynak planlanması sonucunda hazırlanan raporlarda ekonomik fonksiyonların getirilerinin yanında odun dışı orman ürünlerinin ve hizmetlerinin yer alması gerekmektedir. Bal ormanları ve bal üretimi de bu hizmetlerin bazılarıdır (Güngör ve Ayhan 2015). 
Aynı ürünün çok geniş tarım işletmelerinde veya ormanlarda yetiştirilmesinin artması sonucunda bitkilerin böceklerden zarar gördüğünde hastalık hızlı bir şekilde yayılır ve tüm tarım arazisine arız olur. Bu da o alanda bitki ve böcek ilaçlarının kullanılmasını doğurur. Bu tür ilaçlar ise özellikle arıların nektarlarını kullandığı bitkileri verimsiz hale getirir. Son zamanlarda bu zararlılarla mücadele, kimyasal yolla değil de biyolojik yolla yapılmaktadır. Bu tarz biyolojik mücadele görmüş alanlar hem nektar hem verim hem de elde edilecek balların kalitesini de artıracaktır. (Orman Atlası 2013).

Bal üretiminin büyük bir çoğunluğunu ormanlar ve orman vasfını kaybetmiş alanlar oluşturmaktadır. Bozuk orman alanlarının verimli alanlara dönüştürülmesi ekonomik, sosyal ve çevresel faydaları artırırken, orman köylüsü için de ekonomik bir katkı sağlayacak bunun sonucunda ormanlara ve ağaçlara olan baskı azalacaktır. Aynı zamanda bal ormanları hem orman köylüsü hem de yöre halkı için bir iş kapısı olacağı düşünülmektedir. İşsizliğin azalması da ülkemize pozitif yönde bir katkı sağlayacak, üretimi artıracaktır (BOEP 2013).

"Bursa Orman Bölge Müdürlüğü Sınırlarında Bulunan Bazı Odunsu Türlerle Kurulabilecek Potansiyel Bal Ormanı Alanlarının Belirlenmesi" adlı çalışmamızda, Bursa Orman Bölge Müdürlüğü sınırlarındaki bal ormanı olabilecek potansiyel orman alanlarının belirlenmesi ve ileride yapılabilecek bal ormanlarının konumlarının karar verilmesine yardımcı olabileceği beklenmektedir. Bu sayede sosyal ormancilığa, orman köylüsüne ve arıcılığa katkı sağlayacağı düşünülmektedir.

Araştırmamızda çalışma alanı olarak Bursa Orman Bölge Müdürlüğü ormanlık alanları seçilmiş olup, Bursa yöresindeki bal ormanı üretim alanlarını ve potansiyellerinin belirlenmesi amacıyla Bursa Orman Bölge Müdürlüğü Amenajman Planları (2017), OGM Bal
Ormanı Eylem Planı (2013), Bal Ormanları İşletilmesi ve Yönetilmesi Tebliği ile bazı illerde yürütülen Bal Ormanı Projelerinden (OGM 2011; OGM 2012) ve çeşitli istatistiki verilerden (TÜiK 2017; FAO 2017) yararlanılmıştır.

\section{MATERYAL VE METOT}

Araştırma sahası Bursa, Bilecik, İnegöl, Keles, Mustafakemalpaşa, Orhaneli ve Yalova Orman İşletme Müdürlüklerini barındıran Bursa Orman Bölge Müdürlüğüdür (BOBM) (Şekil 1). BOBM sınırlarında kurulan bal ormanları TÜik (Türkiye İstatistik Kurumu) aracılığıyla elde edilmiş olup 2013-2017 tarihleri arasında 6 adet bal ormanı kurulmuştur. Yapılan çalışma kapsamında potansiyel bal ormanı sahalarını belirlememiz için gerekli olan odunsu türler, bal ormanı eylem planlarına ve projelerine bakılarak hem nicelik hem de nitelik anlamında verimli olan Ihlamur ve Kestane olarak belirlenmiştir. Bu türlerin saf ve karışıma girmiş olan meşcereleri araştırmaya konu olan alanlar olarak ele alınmıştır. Dijital veriler incelenerek bal ormanı olabilecek uygun sahalar, çeşitli kriterler sonucunda önerilmiştir.

BOBM 07.02.1951 tarihinde kurulmuş olup, Bursa, Bilecik ve Yalova illerini kapsamaktadır. Bünyesinde 7 işletme Müdürlüğü mevcuttur. Bu İşletme Müdürlüklerinin orman varlığı Çizelge 1'de verilmiştir. BOBM'nin genel alanı 1.555 milyon hektar olup, bunun 749 bin hektarı ormanlık alan, 806 bin hektarı ormansız alandır.

$\mathrm{Bu}$ çalışmada BOBM öncelikle, sınırları içerisinde kurulacak olan bal ormanlarının potansiyel alanlarının belirlenmesinde kullanılabilecek alanlar belirlenmiştir. Buna göre Arc/Info 10.5 programı aracılığıyla BOBM'ne ait sayısallaştırıımış haritalar kullanılarak alana ilişkin eğim, yükselti, rüzgâr, sulak alanlar ve iskân haritaları oluşturulmuştur. Elde edilenler Arc/Info programı ile analiz edilmiştir. 
Şekil 1. Bursa Orman Bölge Müdürlüğü haritası

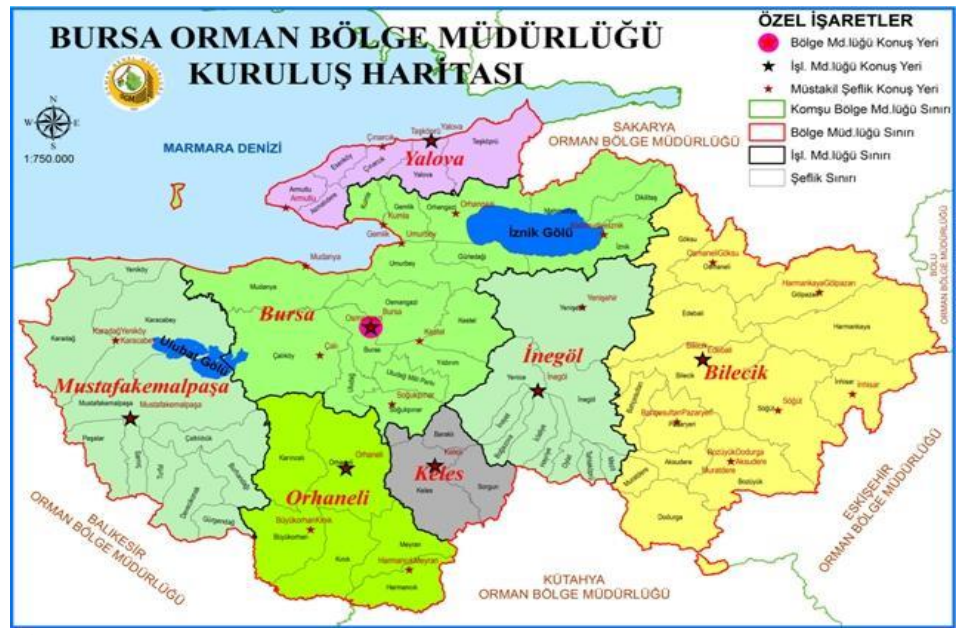

Çizelge 1. Bursa Orman Bölge Müdürlüğü orman varlığı.

\begin{tabular}{llllll}
\hline İşletme müdürlügü & Normal orman (Ha) & Bozuk orman (Ha) & Toplam orman alanı (Ha) & Ormansız alan (Ha) & Genel alan (Ha) \\
\hline Bursa & 135.396 & 93.253 & 228.649 & 190.879 & 419.528 \\
Bilecik & 98.431 & 51.958 & 150.389 & 212.201 & 362.590 \\
İnegöl & 47.616 & 20.114 & 67.730 & 110.899 & 178.629 \\
Keles & 21.312 & 15.354 & 36.666 & 27.762 & 64.428 \\
Mustafakemalpaşa & 80.976 & 31.940 & 112.916 & 160.075 & 272.991 \\
Orhaneli & 65.684 & 41.569 & 107.253 & 71.576 & 178.829 \\
Yalova & 35.958 & 10.655 & 46.613 & 32.573 & 79.186 \\
\hline Toplam & $\mathbf{4 8 5 . 3 7 3}$ & $\mathbf{2 6 3 . 8 4 3}$ & $\mathbf{7 4 9 . 2 1 6}$ & $\mathbf{8 0 5 . 9 6 5}$ & $\mathbf{1 . 5 5 5 . 1 8 1}$ \\
\hline
\end{tabular}

Kestane (Castanea sativa Mill.), ülkemizde yaklaşık 111 hektar yer kaplamakta olup, bal üretimi bakımından önemli bir ağaç türü olan kestaneden bol çiçeklenme dönemlerine göre dönümde 20-25 kg bal elde edilmektedir. Uzun süre saklanabilme özelliğine sahip kestane balı acımtırak ve rengi koyudur. Özellikle nemli sıcak mevsim ve havalarda verimi yüksektir. (Orman Atlası 2013).

Ihlamur (Tilia spp.), ülkemizde yaklaşık 12 hektar yer kaplamakta ve özellikle Karadeniz bölgesinde yayılış göstermekte olup, ıhlamur bal nektarı ve aroması için önemli bir bitkidir. Balı çok rağbet görür ve dökülen yaprakları toprağı iyileştirmektedir. (Orman Atlası 2013).

Potansiyel bal ormanlarından elde edilen balların satış fiyatları Tüik verilerinden elde edilerek hesaplanmıştır.

Bal ormanlarının kurulması için gerekli olan kriterlere Bal Ormanı Eylem Planından ulaşılmıştır. Kriterlere sahip alanlar bulgular kısmında gösterilmiştir. Bu kriterler;
- En az rüzgâr tutan yer olmalıdır.

- Trafiğin fazla olduğu alanlarda yoldan en az 200 metre, stabilize yollarda ise en az 30 metre uzaklıkta yer almalıdır.

- Insan ve hayvan hareketlerinden uzakta olmalıdır.

- Özellikle trafikten etkilenmeyecek alanlar olmalıdır.

- Yakınında sürekli olarak temiz su sağlayan bir kaynak bulunmalıdır.

- Arıcılığın yoğun olduğu bölgeler ile talebin fazla olduğu yerler seçilmelidir.

- En az 20 hektar alan olmalıdır (BOEP 2013).

\section{BULGULAR VE TARTIŞMA}

Dünyada arıcılıkta bal üretiminde, 2010-2016 yılları arasındaki verilere göre 451 bin ton ile Çin birinci sırada iken, ikinci sırada 97 bin ton ile Türkiye; daha sonra sırasıyla 71 bin ton ile ABD ve 68 bin ton ile İran gelmektedir (BOEP 2013). Son yıllardaki gelişmelerden dolayı ülkemiz dünyanın en önemli ikinci bal üreticisi durumuna gelmiştir (Güngör ve Ayhan 2015). Ülkemiz, 
kovan sayısı anlamında dünyada ilk üçte olmasına rağmen, kovan başına 16 kilogram bal üretimiyle dünya ortalaması olan 20 kilogramın altında bulunmaktadır. Ayrıca dünyadaki bal ürünleri pazarında 10 . sırada bulunan ülkemiz, sahip olunan kovan sayısı ile bal üretimi arasında doğrusal bir ilişki bulunmamaktadır. Hem dünyadaki bal ticareti hem de koloni başına bal üretimi bakımından; ülkemizin arıcılıktaki potansiyelden yeterince faydalanamadığı aşikârdır (BOEP 2013). İstatistiklere bakıldığında ise Türkiye gerek arıcılıkla uğraşanlar gerekse kovan varlığı bakımından üst sıralarda olmasına rağmen üretilen arı ürünleri bakımından birçok ülkeden geride bulunmaktadır (Güngör ve Ayhan 2015). Türkiye'deki bal ormanlarının sayısal ve alan olarak dağılımını ele aldığımızda; 2018 yılı itibari ile bal ormanı sayımız 424 olmuştur (Anadolu Ajansı 2018). Bal ormanlarının 2013- 2017 tarihleri arasındaki sayısal dağılımları Şekil 2'de alansal dağılımları ise Şekil 3'de verilmiştir. Aynı zamanda 2012 yılında CBS şubesi tarafından yapılan Türkiye'nin bal ormanları haritası da Şekil 4'de verilmiştir.

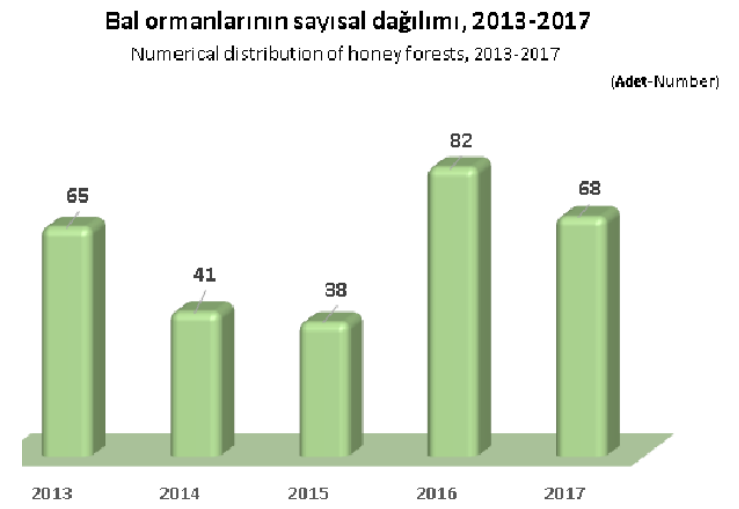

Şekil 2. Türkiye'deki bal ormanlarının sayısal dağılımı

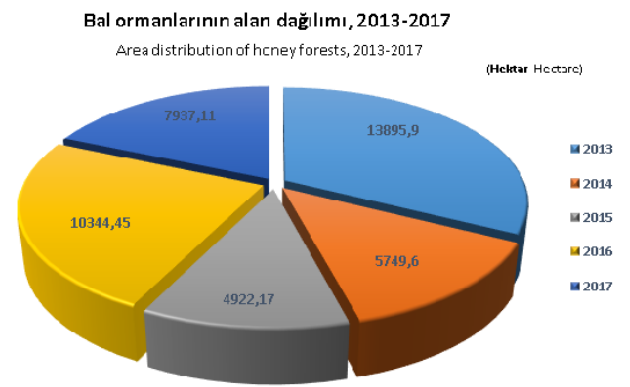

Şekil 3. Türkiye'deki bal ormanlarının alansal dağılımı

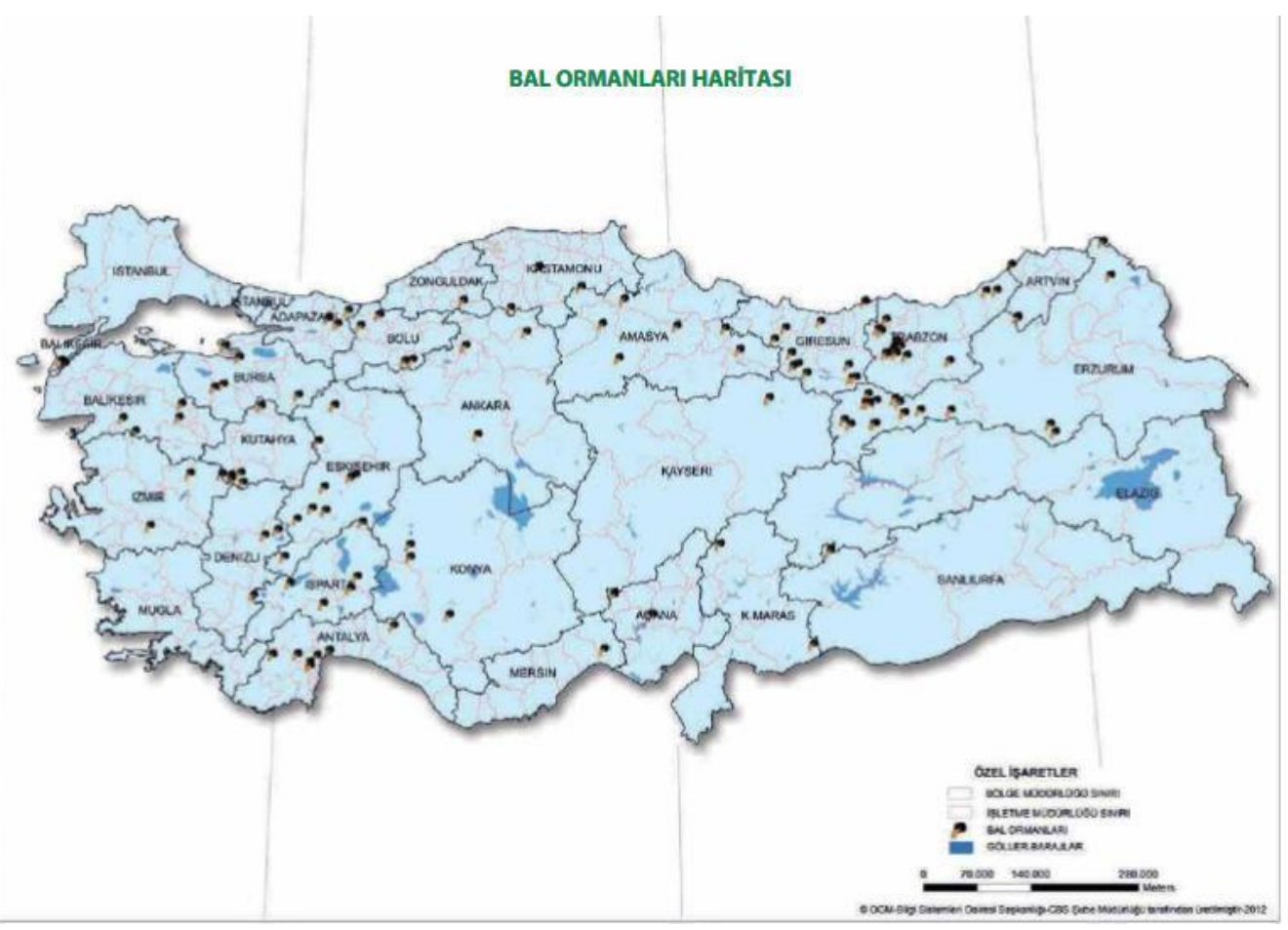

Şekil 4. Türkiye'deki bal ormanları haritası (OGM 2012)

Ülkemiz hem bitki örtüsü hem de eşsiz iklim ve coğrafik özellikleri ile arıcılık bakımından son derece elverişli bir ortam oluşturmaktadır. Türkiye bulunduğu konum, iklim ve bitki örtüsü ile ideal bir arıcılık bölgesidir. TÜiK 2017 verilerine göre çalışma alanımız olan Bursa OBM'de bulunan Yalova ve Bursa ilinde 2017 yılında sırasıyla, 311 ton ve 980 ton bal üretimi yapılmıştır. Bu balın yaklaşık \%70'i Kestane, \%30'i çiçek balı olarak üretilmiş olmasına 
rağmen piyasadaki arz talep dengesi ile bu oranlar yıldan yıla değişmektedir.

Çalışma alanımız olan Bursa Orman Bölge Müdürlüğü sınırları Şekil 5’te belirtilmiştir. Bal Ormanı Eylem Planında yer alan kriterler ışığında ihtiyacımız olan haritalarla (eğim, yükselti, sulak alanlar, iskân ve rüzgâr haritaları) desteklenerek potansiyel bal ormanı olabilecek alanlar belirlenmeye çalışıımıştır.

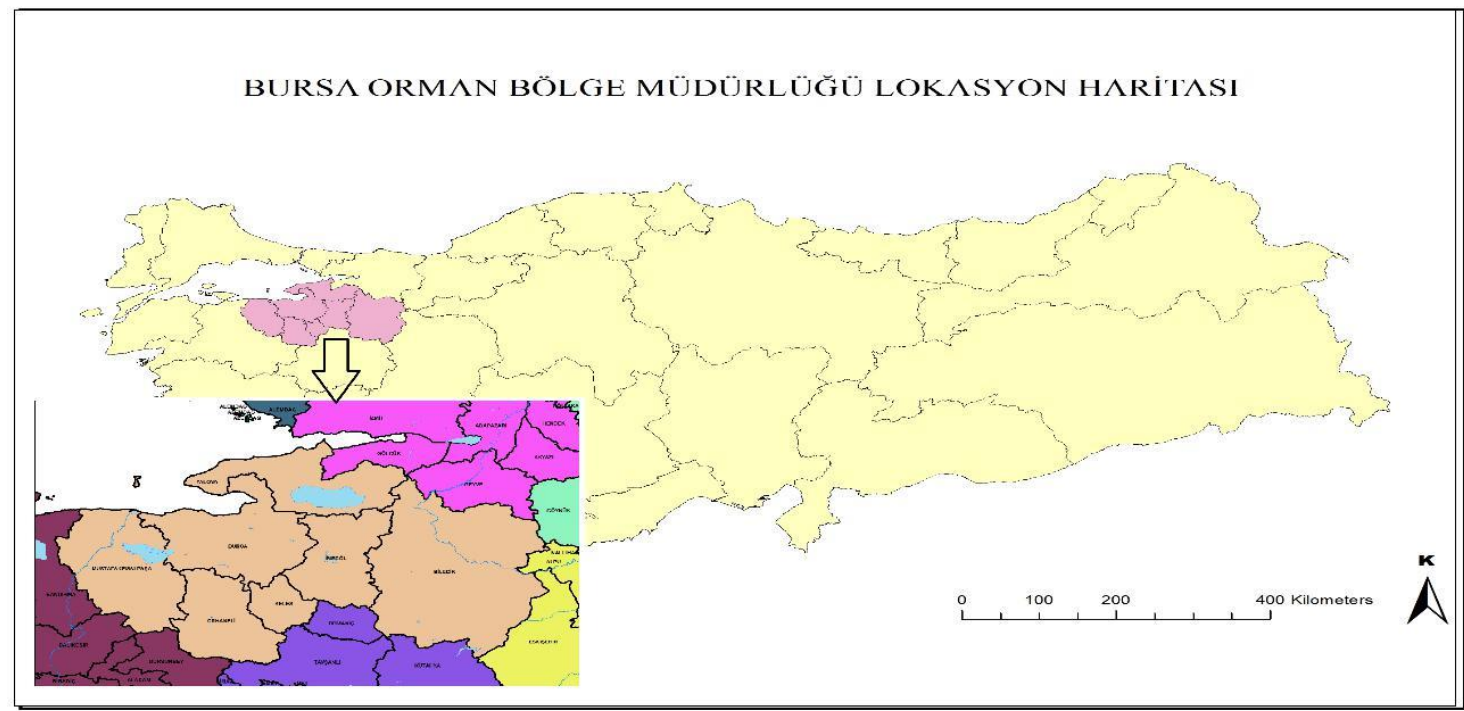

Şekil 5. Bursa Orman Bölge Müdürlüğü lokasyon haritası

Yenilenebilir Enerji Genel Müdürlüğünden alınan bölge bazındaki rüzgâr haritaları kullanılarak en az rüzgâr alan bölgeler Şekil 6'da belirtilmiş̧ir. Kırmızı renkten mavi renge doğru giden skalada mavi renkli olan alanlar en az rüzgâra sahip bölgelerdir.

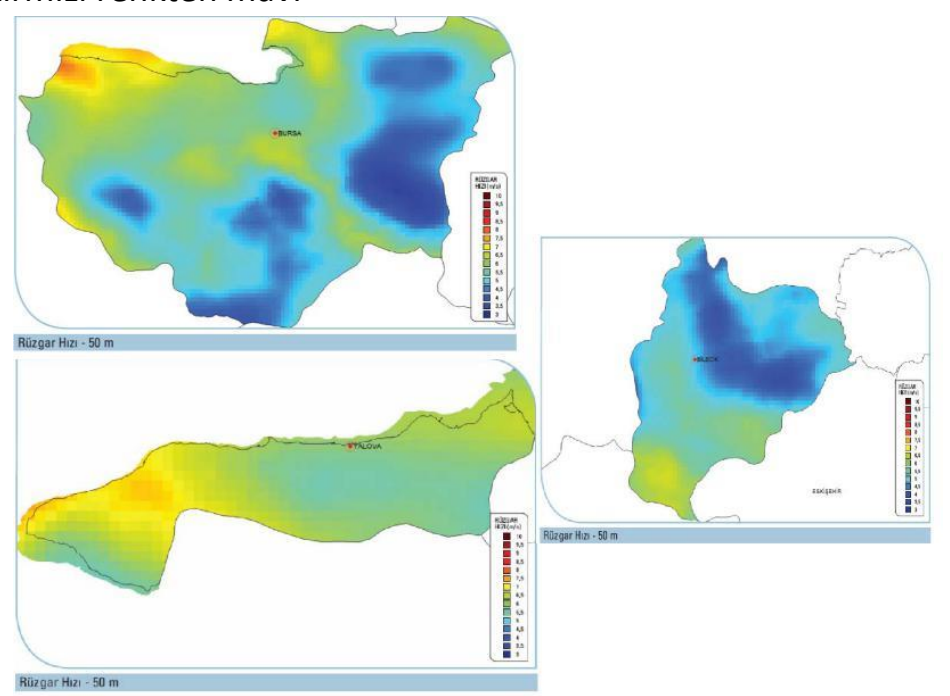

Şekil 6. Yenilenebilir enerji genel müdürlüğünden alınan rüzgâr haritaları

Orman amenajman planlarından elde edilen veriler ışı̆̆ında bal ormanı olarak seçilen Kestane ve Ihlamur meşcereleri incelenerek harita oluşturulmuştur. Söz konusu potansiyel haritalar oluşturulurken, meşcerelerin en az 20 ha olmasına, en az rüzgâr almasına ve iskân alanlarından uzakta olmasına dikkat edilmiştir (Şekil 7). 


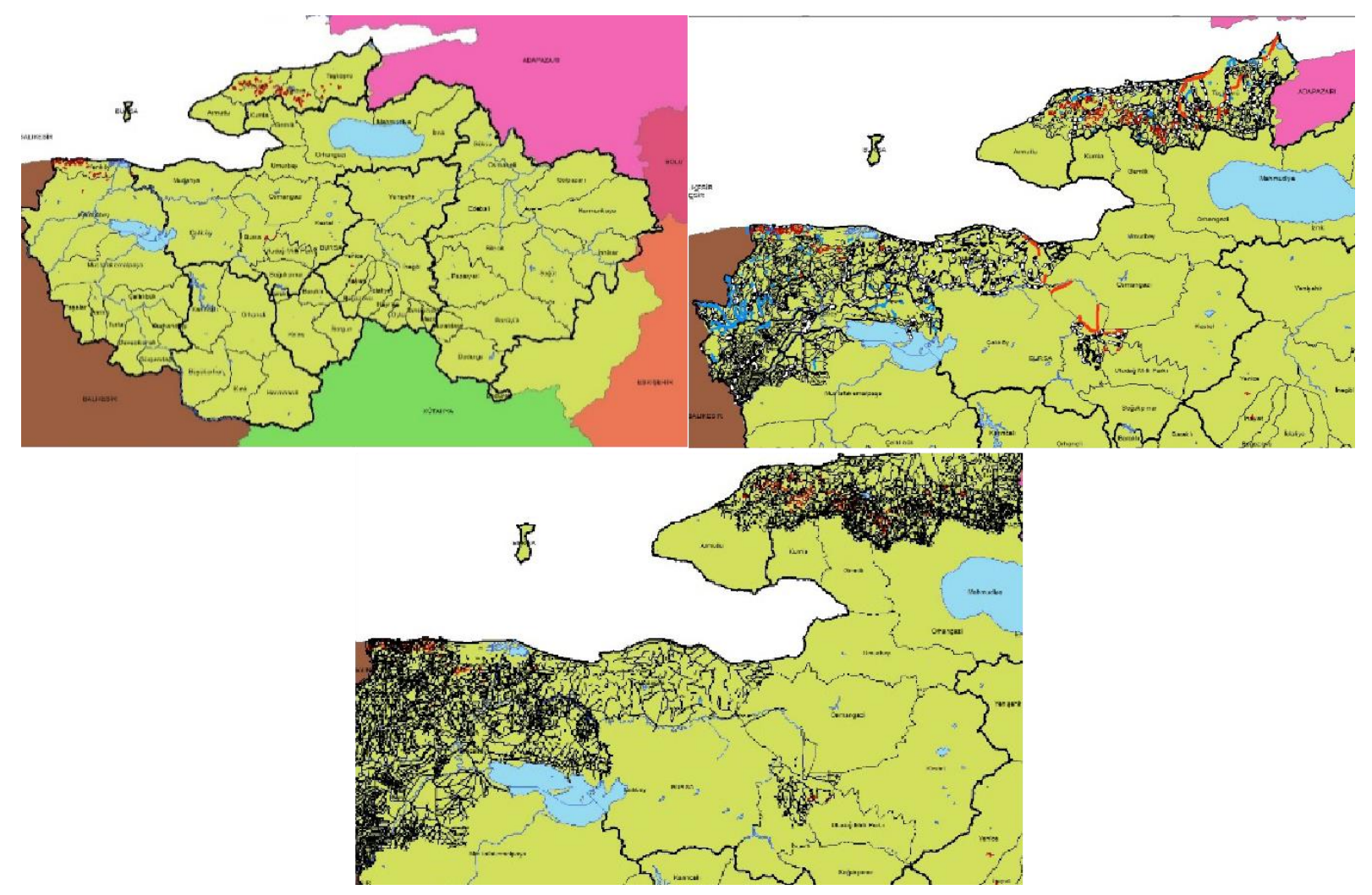

Şekil 7. Potansiyel bal ormanı alanlarının lokasyon ve yol ağları

Elde edilen sonuçlara göre bal ormanı kurulabilecek alanlar, Kestane ve Ihlamur ormanlarının çoğunlukta olduğu BOBM Yalova OiM ve Mustafakemalpaşa OіM sınırları içerisinde bulunmaktadır. Bu alanlar harita (Şekil 8) ve öznitelik tablosunda (Çizelge 2 ) gösterilmiştir.

Çizelge 3'e göre BOBM genelinde; toplam 487 ha Potansiyel Bal Orman (PBO) alanı, Kestane, Ihlamur, diğer

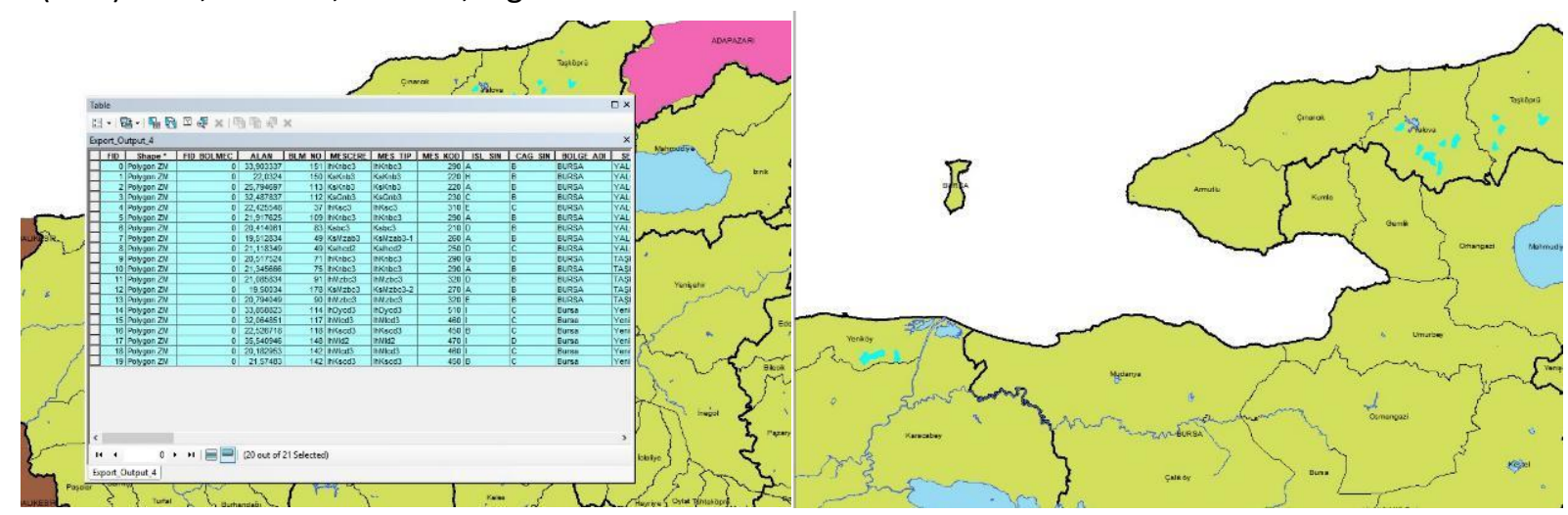

Şekil 8. Potansiyel bal ormanı alanları otsu ve ballı bitkiler ile kaplıdır. Buna göre Bursa yöresi için belirlenen PBO alanlarında 2013 yılında yayımlanan eylem planına göre hektar başına ortalama $250 \mathrm{~kg}$ bal üretimi potansiyeli olduğu biliniyorsa, üretim potansiyeli yaklaşık 122 ton (121750 kg=487 ha $\times 250 \mathrm{~kg} / \mathrm{ha}$ ) olarak bulunmuştur. 
Çizelge 2. Potansiyel bal ormanı alanları

\begin{tabular}{|c|c|c|c|c|}
\hline Bölme No & Meşcere Tipi & Alanı (ha) & İşletme Adı & Şeflik Adı \\
\hline 178 & KsMzbc3 & 20 & YALOVA & TAŞKÖPRÜ \\
\hline 49 & KsMzab3 & 20 & YALOVA & YALOVA \\
\hline 142 & IhMlcd3 & 20.1 & M.KEMALPAŞA & YENIKÖY \\
\hline 83 & Ksbc3 & 20.4 & YALOVA & YALOVA \\
\hline 71 & IhKnbc3 & 20.5 & YALOVA & TAŞKÖPRÜ \\
\hline 90 & IhMzbc3 & 20.8 & YALOVA & TAŞKÖPRÜ \\
\hline 91 & IhMzbc3 & 21 & YALOVA & TAŞKÖPRÜ \\
\hline 49 & Kslhcd2 & 21.1 & YALOVA & YALOVA \\
\hline 75 & IhKnbc3 & 21.3 & YALOVA & TAŞKÖPRÜ \\
\hline 142 & IhKscd3 & 21.5 & M.KEMALPAŞA & YENIKÖY \\
\hline 109 & IhKnbc3 & 21.9 & YALOVA & YALOVA \\
\hline 150 & KsKnb3 & 22 & YALOVA & YALOVA \\
\hline 37 & IhKsc3 & 22.4 & YALOVA & YALOVA \\
\hline 118 & IhKscd3 & 22.5 & M.KEMALPAŞA & YENIKÖY \\
\hline 113 & KsKnb3 & 25.8 & YALOVA & YALOVA \\
\hline 117 & IhMlcd3 & 32 & M.KEMALPAŞA & YENIKÖY \\
\hline 112 & KsGnb3 & 32.5 & YALOVA & YALOVA \\
\hline 114 & IhDycd3 & 33.8 & M.KEMALPAŞA & YENIKÖY \\
\hline 151 & IhKnbc3 & 33.9 & YALOVA & YALOVA \\
\hline 148 & IhMld2 & 33.5 & M.KEMALPAŞA & YENIKÖY \\
\hline
\end{tabular}

Çizelge 3. ВOBM ve ilgili şefliklerde potansiyel bal orman alanları ve yüzdeler

\begin{tabular}{lccccc}
$\begin{array}{c}\text { Orman işletme } \\
\text { şefliği }\end{array}$ & $\begin{array}{c}\text { Potansiyel bal } \\
\text { ormanı (Ks+Dy) }\end{array}$ & $\begin{array}{c}\text { Potansiyel bal } \\
\text { ormanı \% (Ks+Dy) }\end{array}$ & $\begin{array}{c}\text { Potansiyel bal } \\
\text { ormanı (lh+Dy) }\end{array}$ & $\begin{array}{c}\text { Potansiyel bal } \\
\text { ormanı \% (Ih+Dy) }\end{array}$ & $\begin{array}{c}\text { Potansiyel bal } \\
\text { ormanı toplam } \\
\text { alan(ha) }\end{array}$ \\
\hline TAŞKÖPRÜ & 20.00 & $12.36 \%$ & 83.6 & $25.71 \%$ & 103.6 \\
YALOVA & 141.8 & $87.64 \%$ & 78.2 & $24.05 \%$ & $21.27 \%$ \\
YENIKÖY & 0.00 & $0.00 \%$ & 163.4 & $50.25 \%$ & 16.00 \\
\hline BOBM Toplam & 161.8 & $100.00 \%$ & 352.2 & $100.00 \%$ & $35.17 \%$ \\
\hline
\end{tabular}

Bursa Orman Bölge Müdürlüğü sınırları içinde toplamda 487 hektarda, 122 ton (122.000 kg) potansiyel bal üretimi olup, 2018 yılında çalışmanın yapıldığı göz önüne alındığında kilogram başına ortalama satış fiyatı 22.8 \$ (Toplam Gelir / Bal Ürünleri Toplamı) olduğu düşünülürse, Bursa OBM genelinde potansiyel bal ormanı alanlarından yaklaşık 2.7 milyon dolar (2.781.600 \$=122.000 kg $\times 22,80 \$$ ) bir gelir sağlanmış olacaktır (Çizelge 4).

Çizelge 4. Bal çeşitlerinin satışından elde edilebilecek gelirler.

\begin{tabular}{lccc}
\multicolumn{1}{c}{ Arı ürünü çeşidi } & $\begin{array}{c}\text { Satış miktarı } \\
(\mathrm{kg})\end{array}$ & $\begin{array}{c}\text { Satış fiyatı } \\
(\$)\end{array}$ & $\begin{array}{c}\text { Toplam gelir } \\
(\$)\end{array}$ \\
\hline Kestane Balı & 904 & 24 & 21.696 \\
Ihlamur Balı & 388 & 20 & 7.760 \\
Bal Ürünleri & 1292 & 44 & 29.456 \\
Toplamı & & & \\
Ortalama (kg / \$) 22.80 \$ & &
\end{tabular}

\section{SONUÇLAR}

Günümüzde odun dışı orman ürünlerinde gerekenden az ve bilinçsiz bir planlama yapılmaktadır. Bundan dolayı bu ürünleri planlarken uzman kişilere danışılmalı ve onlarla iş birliği noktasında özenli çalışmalar yapılmalıdır (Küçüker ve ark. 2010).

Ülkemizde bal verimi ve üretimi konusunda yeteri kadar çalışma bulunmazken, bu tür çalışmalar yapılacağında, bölge veya il bazında bal ormanı alanlarının tanımlanması gerekmektedir. Ayrıca o alanlara verim, nektar ve yoğun bal içeren bitkiler ve orman ağaçları dikilmelidir.

Yapılan analizler sonucunda odunsu türler bazında BOBM sınırları içerisinde bal ormanına konu olabilecek alanlar belirlenmiştir. Alanların belirlenmesinde gerekli olan ölçütlere Bal Ormanı Eylem Planından erişilmiştir. 
Yapılan bu çalışma kapsamında elde edilen sonuçlar aşağıda verilmiştir:

- Tespit edilen PBO alanlarının toplamı 487 hektardır. Bu alanların \%70'i Yalova OiM'nde bulunurken \%30'u Mustafakemalpaşa OiM içerisinde yer almaktadır.

- Yapılan görüşme ve gözlemlerle ortalama olarak fiyatların Kestane balında 20-30 \$, Ihlamur-Çiçek balında ise 18-24\$ olduğu düşünüldüğünde geçen yıl 29.456 \$ gelirin elde edildiği görülmektedir (Tablo 4).

- Bursa yöresinde yapılan bal üretim hasat çalışmalarında tek bir tür (Kestane) kullanmak yerine ballı bitkilerin bulunduğu alanlarda yapılacak üretim daha verimli olacaktır. Bal üretiminin kesintisiz devam etmesi ve birden fazla bitki ile üretim yapıldığından dolayı balın kalitesi artmakta, bal üreticisi tarafından da bu sahalar oldukça talep görmektedir

- Bal ormanlarının kurulması, ormanlardan sürdürülebilir bir şekilde ekonomik, ekolojik ve sosyal fonksiyonları kullanarak yararlanmamızı sağlamaktadır.

- Çalışma kapsamında belirlenen potansiyel bal ormanı alanlarında arıcılık potansiyelinin irdelenmesi ve değerlendirilmesi sonucunda elde edilecek gelir, sosyal olarak da yöreye ek gelir sağlayacaktır. Bunun sonucunda ise refah düzeyinde gözle görülür bir fark meydana geleceği beklenmektedir.
Bu çalışma, yapılacak olan yeni bal ormanlarına lokasyon olarak zemin hazırlayabilir. Farklı parametreler de eklenip sonuç tartışılabilir ve genişletilebilir.

\section{KAYNAKLAR}

Anadolu Ajansı, (2018) Bal ormanı sayısı 424'e ulaştı. http://www.hurriyet.com.tr/ekonomi/bal-ormani-sayisi-424eulasti-40937287

BOEP (2013) Bal Ormanı Eylem Planı. Orman ve Su Bakanlığı, OGM Yayınları, Ankara.

Crane E (1972) Bees in the pollination of seed erops. J. Royal Agri.Soc. England. 19:133

Crane E (1975) Honey a Comprehensive Survey. Heinemann, London

Küçüker DM, Başkent EZ, Günlü A (2010) III. Ulusal Karadeniz Ormancllık Kongresi, 302-313

FAO (2017) BM Gıda ve Tarım Örgütü, FAOSTAT

Güngör E, Ayhan A (2015) Bartın yöresi orman kaynaklarının bal üretim potansiyeli ve ekonomik değeri. Turkish Journal of Forestry, 17 (1), 108-116

OGM (2010) Bal Ormanları. Orman ve Su Bakanlığı, OGM Yayınları, http://balormani.ogm.gov.tr

OGM (2011) Arhavi Bal Ormanı Projesi. http://balormani.ogm.gov.tr OGM (2012) Bayat Bal Ormanı Projesi. http://balormani.ogm.gov.tr

OGM (2014) Türkiye Ormanları, http://www.ogm.gov.tr/Sayfalar/Ormanlarimiz/IllereGoreOrman-Varligi.aspx

Orman Atlası (2013) Orman ve Su İşleri Bakanlığı, OGM Yayınları, https://www.ogm.gov.tr/ekutuphane/Yayinlar/Orman\%20Atlasi. pdf

TÜiK (2017) Türkiye İstatistik Kurumu, Hayvancllık İstatistikleri, http://www.tuik.gov.tr/HbGetir.do?id=27704\&tb_id=4 